Revista Iberoamericana, Vol. LXXVII, Núm. 234, Enero-Marzo 2011, 195-211

\title{
LA FRONTERA QUE EMBIZCA: RETÓRICA VISUAL Y LA CONSTITUCIÓN DEL SUJETO EN MIGRA MOUSE DE LALO ALCARAZ
}

\author{
POR \\ ISRAEL REYES \\ Dartmouth College
}

En su ensayo, “The Evidence of Experience”, Joan Scott escribe: “La experiencia no es [...] el origen de nuestra explicación, sino lo que queremos explicar" ("Experience is [...] not the origin of our explanation, but that which we want to explain”) (797). Para Scott, su proyecto como historiadora del sujeto marginado ${ }^{1}$ es cuestionar, desafiar y contestar a las metodologías historiográficas que plantean una relación transparente y natural entre la experiencia personal de un sujeto y el uso de esa experiencia (sea en su forma narrativa o visual) para crear "evidencia”. Ella propone un análisis que pueda exponer la lógica interna de los mecanismos represivos que ocultan a los sujetos marginados de la historia, y expone cómo la diferencia está constituida por un proceso relacional (779). Para elaborar este análisis, hay que atender a los procesos históricos ("we need to attend to the historical processes") que posicionan a los sujetos y producen sus experiencias discursivamente (779). Según Scott, los individuos no tienen sus propias experiencias, sino que la experiencia constituye a los sujetos ("It is not individuals who have experience, but subjects who are constituted through experience”) (779). Esta tesis historiográfica refleja la teorización de los textos autobiográficos que articula John Paul Eakin, quien propone que la narrativa no es sólo una forma literaria sino un modo de auto-experiencia fenomenológica y cognitiva ("a mode of phenomenological and cognitive self-experience"), mientras que el "yo" del discurso autobiográfico no precede necesariamente su constitución en la narrativa (“does not necessarily precede its constitution in narrative”) (100). Tanto Scott como Eakin invierten el orden semántico que sitúa las experiencias personales como punto de origen desde el cual el sujeto visualiza su lugar en la historia y la sociedad. Es el espacio discursivo el que establece los parámetros narrativos que el sujeto utiliza para visualizar y comprender sus experiencias como parte de un proceso histórico.

1 Mientras que en este ensayo Scott desarrolla sus teorizaciones a partir de un análisis de las memorias del novelista y activista homosexual Samuel Delany, la mayoría de sus publicaciones se enfoca sobre el feminismo y la historia, sobre todo en Francia. Véase Gender and the Politics of History (1988), Only Paradoxes to Offer: French Feminists and the Rights of Man (1996), Parité!: Sexual Equality and the Crisis of French Universalism (2005) y The Politics of the Veil (2007). 
La experiencia personal y su articulación, sea en la literatura, el arte, el teatro o el cine, ha sido fundacional para entender cómo se ha constituido al sujeto latino fronterizo en los Estados Unidos. Desde las novelas autobiográficas de Sandra Cisneros y Oscar Zeta Acosta a las películas de Gregory Nava, la experiencia personal ha servido de eje orientador para localizar al sujeto latino en la historia y en la geografía ontológica. El historietista chicano Lalo Alcaraz (1964-) invoca esa función orientadora para organizar y lanzar la colección de sus viñetas que satirizan la experiencia de la frontera entre México y EE.UU. Migra Mouse: Political Cartoons on Immigration (2004) podría haber sido una simple antología de imágenes en viñetas dispersas que trataran los temas de la frontera, ${ }^{2}$ la inmigración, la labor migratoria, el debate sobre el idioma y la política internacional. Sin embargo, es la experiencia propia del historietista -que se presenta en forma de una historieta introductoria- la que antecede y constituye el significado de las otras imágenes que se habían publicado a lo largo de la carrera de Alcaraz. O, ¿¿es el caso que los dibujos son el discurso que constituye al Lalo Alcaraz que aparece en la historieta, y que su voz y visión de la frontera son efectos de los procesos históricos que se caricaturizan en los dibujos? Siguiendo las metodologías de Scott y Eakin, se podría considerar que los dibujos antologados de Alcaraz explican la representación de su experiencia, la cual se articula posteriormente como una narrativa autobiográfica. La naturaleza incongruente del humor en las imágenes de Migra Mouse requiere un análisis de la comicidad, sobre todo el relajo y su rol en la formulación del espacio discursivo desde el cual el autor visualiza y conceptualiza sus experiencias. El modo autobiográfico de la historieta sitúa la experiencia incongruente de la frontera en el origen de la visión humorística del artista, pero podría argumentarse que la retórica visual de la caricatura política es la que constituye discursivamente la subjetividad fronteriza de Alcaraz.

Migra Mouse (Figura 1) deriva su título de uno de los dibujos más conocidos del artista: una reproducción paródica del famoso Mickey Mouse, el ratón de Disney, que está vestido de patrullero del Servicio de Inmigración y Naturalización, o la "migra”. ${ }^{3}$ El Migra Mouse, que aparece en la portada de la colección, señala con el dedo no la dirección a Disneylandia, sino el camino de regreso a México para que los inmigrantes mexicanos vuelvan a su país de origen. La colección en total consta de una introducción textual, escrita por el artista, una historieta autobiográfica, "Roach Against the Machine”

2 En contraste, Alcaraz publicó ese mismo año otra colección, La Cucaracha (2004), en la cual el artista presenta varios ejemplos de las historietas en que protagoniza el personaje titular. Esta colección carece de una introducción autobiográfica pero sí incluye una serie de personajes que representan diferentes tipos de la comunidad chicana. Por otro lado, Alcaraz colaboró con el crítico y autor Ilán Stavans en una historieta histórica, Latino U.S.A.: A Cartoon History (2000), en que se dibuja la historia desde la época precolombina hasta el momento actual. Aquí se enfoca más en la historia colectiva en vez de las experiencias personales de los autores.

3 La antigua Immigration and Naturalization Service (INS) dejó de existir en 1993 y ahora la mayoría de sus funciones se llevan a cabo en Immigration and Customs Enforcement (ICE).

Revista Iberoamericana, Vol. LXXVII, Núm. 234, Enero-Marzo 2011,
ISSN 2154-4794 (Electrónico) 


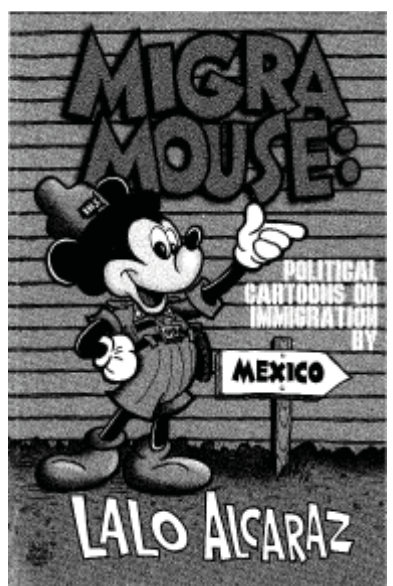

FIGURA 1

Migra Mouse, portada

(La Cucaracha contra el Monstruo 4 ), y nueve capítulos de viñetas caricaturescas, cada cual organizado alrededor de un tema social o una controversia política, pero no necesariamente siguiendo una cronología histórica o de publicación. Además, el último capítulo termina con un epílogo que recapitula los temas y controversias previamente articulados. Apesar de que el primer capítulo, "Our Illegal Forefathers" (Nuestros antepasados ilegales) sí presenta una revaloración de la historia fundacional de los peregrinos (pilgrims) ingleses que emigraron "ilegalmente" como colonizadores, los otros capítulos se enfocan en diversas controversias y acontecimientos recientes sobre la inmigración y la comunidad mexicana en los EE.UU. De todos modos, las primeras dos secciones de dibujos-la historieta autobiográfica y el capítulo sobre los peregrinos- sitúan la experiencia personal del artista dentro de los procesos históricos y el discurso transnacional de la frontera. En su estudio sobre la autobiografía latina en los EE.UU., Silvio Torres-Saillant examina la "indeterminancia epistemológica" ("epitemological indeterminacy" 61) de la escritura autobiográfica y la importancia de la misma en la formación de la identidad colectiva y pública de los latinos en los EE.UU. Dice Torres-Saillant que los autores latinos de autobiografías raramente se escapan de la necesidad de sobreponer lo privado y lo público en sus textos, a saber, el impulso de representar la experiencia colectiva de su comunidad a través de las narraciones de sus vidas individuales ("[...] these authors will rarely escape the need to superimpose the private and public in their texts, namely the drive to represent the collective experience of their community through narrations of their own individual lives" 61). Alcaraz, a través del arte gráfico, organiza su colección de viñetas políticas con el mismo "impulso" de situar su experiencia personal dentro de una experiencia colectiva chicana pero, a la vez, en oposición al "monstruo" de los EE.UU. Los detalles de esa narración (autobio) gráfica ostensiblemente le explican al lector la génesis de la visión estética del artista

4 Aunque machine se traduce literalmente a "máquina”, en este contexto se refiere al grupo de roqueros Rage Against the Machine, entre cuyos miembros se encuentra el vocalista chicano Zack de la Rocha, quien tiene un estilo y repertorio que se distinguen por su fuerte mensaje revolucionario y marxista. La traducción que ofrezco integra la famosa frase de José Martí hablando de los EE.UU.: "Viví en el monstruo, y le conozco las entrañas”. Mientras que el uso de machine en el nombre del grupo roquero se refiere más generalmente al sistema capitalista, en el uso de Alcaraz el término representa el orden social, cultural y racial de los EE.UU., el blanco de sus viñetas satíricas y también el de la carta inconclusa de Martí. Véase Carlos Ripoll, José Martí, the United States, and the Marxist Interpretation of Cuban History (1984).

Revista Iberoamericana, Vol. LXXVII, Núm. 234, Enero-Marzo 2011, 195-211 
y el desarrollo de su conciencia política como sujeto marginado y fronterizo. No obstante, los elementos retóricos de sus imágenes, sobre todo en el rendimiento visual de la incongruencia, la contradicción y la paradoja, sobreponen un eje orientador en la explicación narrativa de sus orígenes identitarios, todo lo cual ayuda a explicar cómo el discurso de la frontera constituye la subjetividad de Alcaraz y cómo el artista se sitúa dentro de ese discurso como un actor político.

Para entender este proceso dinámico constitutivo entre el discurso y la subjetividad, es necesario analizar los mecanismos retóricos que facilitan la articulación visual de las caricaturas políticas. Ray Morris, en su ensayo "Visual Rhetoric in Political Cartoons: A Structuralist Approach”, identifica dos sistemas semánticos que estructuran el sentido en las caricaturas políticas: los imperativos retóricos y los procesos de la retórica visual. En su investigación interdisciplinaria, específicamente las de la prensa canadiense, Morris encuentra paralelos entre las teorías sociológicas de Parsons sobre los imperativos funcionales de sistemas sociales y el trabajo semiológico de Greimas y Courtès sobre las modalidades semióticas que vinculan la acción humana con formas de conocimiento e imperativos sociales (197-98). Para Morris, este paralelismo teórico ayuda a entender cómo las caricaturas en las viñetas políticas articulan una posición social e ideológica, además de cómo estas imágenes se dirigen a un público particular, provocando una reacción emocional y promulgando un curso de acción o una actitud ética/moral. Morris teoriza cuatro imperativos retóricos que se asocian con cuatro tipos de conocimiento: el "poder" (pouvoir) con el conocimiento práctico; el "saber" (savoir) con el conocimiento intelectual; el "deber" (devoir) con el conocimiento político; y el "querer" (vouloir) con el conocimiento emocional. Estos cuatro imperativos operan en concierto con varios procesos semánticos de la retórica visual como la condensación, la combinación, la domesticación y la oposición para afectar el contenido de una imagen caricaturesca (200-2). A éstos, Josh Greenberg les añade la transferencia, cuya importancia con respecto a la política y actitud ética/moral de las caricaturas de Migra Mouse examinaré, en breve. Por otro lado, Morris también examina la carnavalización y la hipercarnavalización como un proceso retórico subversivo que afecta la forma de una caricatura (202-3). Adaptando las aportaciones críticas de Mikhail Bakhtin (1968), describe la carnavalización como una representación estilizada de comportamiento espontáneo, una celebración del cuerpo y regocijo de la comunidad física que subvierte el orden social a través de la burla y la comicidad (202). La hipercarnavalización logra el mismo efecto subversivo, pero sin que haya una participación colectiva; el caricaturista toma el rol central del burlador y el público de lectores juega el papel de espectadores que pagan para ver la imagen (203). Como veremos, muchas de las imágenes de Alcaraz emplean la carnavalización para incluir a los lectores chicanos o latinos en un esfuerzo colectivo con determinadas acciones políticas.

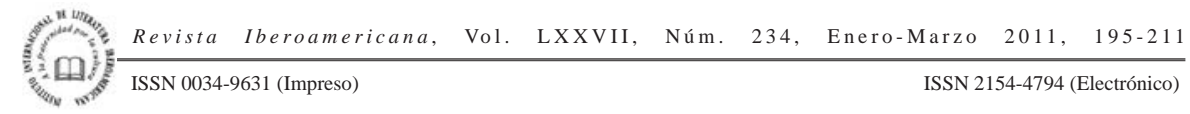


Las categorías analíticas de Morris y Greenberg ayudan a examinar cómo Alcaraz organiza el espacio visual de la caricatura en sus viñetas para plantear su opinión sobre la historia de la frontera y las novedades del mundo actual. Por ejemplo, la imagen de Migra Mouse en la portada de la colección originalmente se publicó en 1994 para denunciar el apoyo financiero que la corporación Disney le dio al gobernador Pete Wilson y su proyecto de Ley 187. Esta ley proponía eliminar servicios públicos para los inmigrantes indocumentados, además de requerir que los empleados públicos en las escuelas y los hospitales delataran a cualquier persona a que sospecharan ser indocumentada. ${ }^{5}$ En su contenido, la imagen de Migra Mouse emplea la combinación, es decir, la yuxtaposición de elementos que derivan de diferentes dominios de significación (Morris 200, Greenberg 187). En el famoso ratón convergen el temible patrullero del SIN y, a la vez, la familiar imagen del letrero que marca la estatura mínima requerida para subirse a las montañas rusas y otros juegos del parque de diversión Disneylandia. En esta viñeta, la regulación del espacio de diversión se combina con las leyes que prohíben acceso a los servicios fundamentales como la educación y la salud. A través de la transferencia, que Greenberg define como un proceso que pone la culpa de algún problema en un blanco u objetivo que está generalmente ausente de la imagen (187), Migra Mouse ataca el sistema capitalista estadounidense ${ }^{6}$ y la explotación del obrero indocumentado que resulta de la complicidad entre la política y la industria. En cuanto a su forma, la imagen es carnavalesca porque efectúa una subversión de la imagen de Disney. Alcaraz relata en la cartela que esta imagen fue reproducida de forma masiva y utilizada en las manifestaciones que se organizaron en contra de la Ley 187. El imperativo retórico del "deber" que articula Migra Mouse promulga la participación a través de la subversión y la desacralización, tal como Mikhail Bakhtin ha descrito lo carnavalesco en Rabelais and His World. Estos procesos retóricos coinciden con los imperativos retóricos del "deber" y el "saber”; la imagen forma parte de una campaña electoral en contra de la Ley 187 y promueve un boicoteo de Disney y sus productos. Además, el uso de la imagen familiar de Mickey Mouse revela un conocimiento político chicano que ve un racismo inherente e implícito en los símbolos apreciados por la cultura angloamericana.

Además de servir como un esquema para analizar las imágenes individuales de Alcaraz, adoptar las teorizaciones de Morris y Greenberg ayuda a examinar cómo el artista utiliza la retórica visual para articular una subjetividad fronteriza desde el espacio discursivo de subversión y oposición. Dice Morris que los caricaturistas, por necesidad, adoptan una posición social, dirigiendo sus obras a una "comunidad de referencia" particular ("Cartoonists necessarily adopt a social position, addressing their work to

5 Para un análisis de este proyecto de ley y los discursos nativistas del momento, véase Robin Dale Jacobson, The New Nativism: Proposition 187 and the Debate over Immigration (2008).

6 La imagen invoca implícitamente el famoso estudio de Ariel Dorfman y Armand Mattelart, Para leer al Pato Donald (1972).

ISSN 0034-9631 (Impreso) 
a particular 'community of reference",7 [197]). Además, con respecto a su temática, Greenberg arguye que las caricaturas “enmarcan” fenómenos al situar el “problema” en cuestión dentro del contexto de la vida cotidiana y, de esta manera, explotan "valores universales" como medio de persuadir a los lectores a identificarse con una imagen y su mensaje intencionado ("Cartoons 'frame' phenomena by situating the 'problem' in question within the context of everyday life and, in this way, exploit 'universal values' as a means of persuading readers to identify with an image and its intended message" [182]). Analizar estos elementos de la retórica visual en las caricaturas de Alcaraz iluminará la manera en que un discurso político -el chicanismo de oposición- ayuda a constituir la subjetividad fronteriza que se representa en la historieta autobiográfica de Migra Mouse. La colección es más que una antología de arte gráfico; es un reclamo por la legitimidad, articulada a través de la narrativización de las experiencias personales del artista, para explicar una visión del mundo. Ala vez, esa visión desde el espacio discursivo de la política antinativista explica la estructuración narrativa de esas experiencias y la retórica visual que las hace significar como conocimiento colectivo.

Según Morris, el primer imperativo del “poder” (pouvoir) se centra en la necesidad de establecer la autoridad del orador, en este caso, el artista de caricaturas. Éste establece su autoridad con el público a través de una demostración de su dominio del vocabulario apropiado y otros símbolos compartidos, sus experiencias personales y su valía de ser escuchado("[...] through demonstrating one's command of the appropriate vocabulary and other shared symbols, one's personal experience, and one's worthiness to be heard" [198-99]). En Migra Mouse, Alcaraz establece este "poder" al comienzo de su colección con un autorretrato (Figura 2) en el que se representa en el acto de dibujar sus caricaturas. El texto que acompaña la imagen dice, "Antes que comencemos, permítanme explicar algunas cosas..."("Before we start, let me explain a few things..." [11]). El autorretrato se dirige directamente al lector, y la caricatura muestra al artista dibujando furiosamente con un desorden de dibujos rechazados y hechos bola a sus pies. Aguanta un vaso desechable de café y lleva unas gafas negras y gruesas que ocupan el centro de la imagen, dominando el espacio visual. Este autorretrato realza el poder creativo del artista, el vigor de su talento, su labor como caricaturista de prensa y la urgencia de su mensaje: “permítanme explicar algunas cosas”. Las

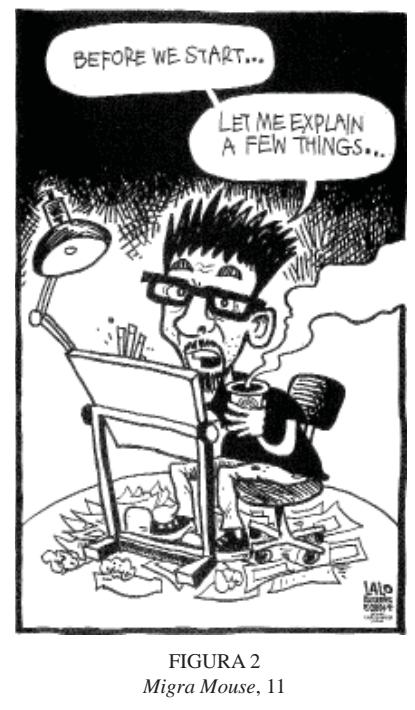

Morris cita esta noción de “community of reference” de Charles Press, The Political Cartoon (1981).

$\begin{array}{lllll}\text { Revista Iberoamericana, Vol. LXXVII, Núm. 234, Enero-Marzo 2011, } & 195-211 \\ \text { ISSN 0034-9631 (Impreso) } & \text { ISSN 2154-4794 (Electrónico) }\end{array}$ 
gafas enormes metaforizan la percepción sobrehumana que ve en los acontecimientos de la actualidad una verdad subyacente. Dice Morris que los caricaturistas a veces alegan sustituir la apariencia interior por la exterior, revelando a través de la exageración y la distorsión el carácter "verdadero" de la persona representada. Al hacerlo, ellos implícitamente afirman que tienen acceso a un conocimiento interno y una posición de que carece la persona que lee por encima las caricaturas de su diario ("They sometimes claim to substitute inner for outer appearance, revealing by exaggeration and distortion the 'true' character of the person portrayed. In doing so, they implicitly claim access to inside knowledge and a position that the person skimming their cartoons in the daily paper lacks” [196]). Alcaraz comienza esta narrativa de legitimación situándose en el lugar del artista visionario, cuyas experiencias personales, rendidas en su producción prolífica, explican la verdad y la realidad de la frontera.

Morris también arguye que el imperativo retórico del “poder”, que se asocia con un conocimiento práctico, pone al artista en un rol heroico, mientras que desacredita a sus rivales como villanos o tontos que merecen ser burlados: "Placement of oneself as autor or artist in the heroic role involves a narrative that discredits certain rivals as unheroic, locating them as villains to be overcome or fools to be mocked, while pointing to one's own solid credentials" (199). En Migra Mouse, este imperativo de legitimar a través de desacreditar se ve claramente si se compara el autorretrato que comienza la colección con una de las caricaturas que Alcaraz hace del ensayista y periodista Richard Rodriguez (Figura 3). El autor de tres colecciones de ensayos, todos vinculados por un fuerte hilo autobiográfico, y productor de breves “ensayos” televisivos para la cadena pública PBS, ${ }^{8}$ no concuerda con la política chicanista que promueve tanto Alcaraz como la mayoría de los intelectuales, escritores o artistas chicanos. A pesar de ser hijo de inmigrantes mexicanos, igual que Alcaraz, Rodriguez ha

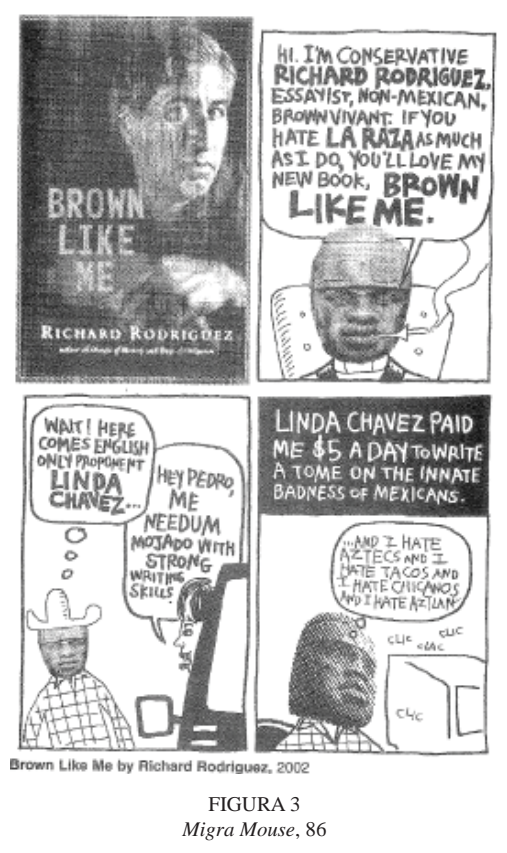

8 Hunger of Memory: The Education of Richard Rodriguez (1982); Days of Obligation: An Argument with My Mexican Father (1992, nominado para el Premio Pulitzer); Brown: The Last Discovery of America (2002). Las transcripciones de los "ensayos" televisivos que Rodriguez produjo para el programa The NewsHour with Jim Lehrer, pueden encontrarse en Online NewsHour: Richard Rodriguez Essays, $<$ http://www.pbs.org/newshour/essays/richard_rodriguez.html>.

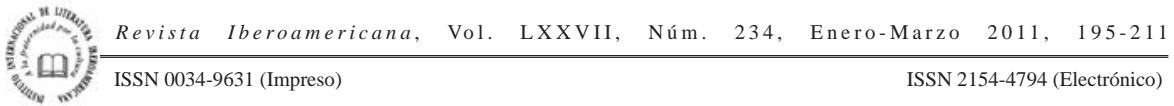


sido criticado por muchos de sus coetáneos ${ }^{9}$ porque no “enmarca” sus experiencias dentro de la política subversiva y de oposición que, históricamente, ha caracterizado al Movimiento Chicano. ${ }^{10}$ Además, Rodriguez ha abogado en contra de la educación bilingüe y la Affirmative Action, todo lo cual ganándole elogios de la prensa mayoritaria pero el desdén de la comunidad intelectual chicana de izquierda. Por consiguiente, en la caricatura de Rodriguez, Alcaraz desacredita al ensayista a través del proceso retórico de la oposición, que Greenberg define como un proceso que reduce la complejidad de un problema o acontecimiento a una lucha binaria ("opposition is a process whereby the complexity of a problem or event is reduced to a binary struggle” [187]). Es decir, los sujetos de herencia mexicana que no adoptan la identidad y la política chicanas están al otro lado de la lucha activista. Alcaraz emplea la transferencia para hacer que la inautenticidad y el elitismo de Rodriguez impliquen y condenen el discurso más amplio del asimilacionismo estadounidense, conocido como el famoso "crisol de las razas". Un ejemplo de la combinación de elementos de distintos dominios es el Rodriguez que aparece con una cabeza colosal olmeca, no sólo indicando que es un cabezadura, sino señalando que carga con el peso de sus orígenes raciales. Esta imagen también emplea la domesticación (Morris 200, Greenberg 187) de la remota historia precolombina para que repercuta en la vida cotidiana del lector, quien reconoce a Rodriguez como un iconoclasta. Según Morris, el orador trata a su público como inocentes que hay que avisar contra peligrosos diagnósticos opuestos, y que hay que provocar a reírse de los diagnósticos insensatos, mientras se les revela la superioridad de lo que el orador propone ("The orator treats the audience as innocents who are to be warned against dangerous opposing diagnoses and enabled to laugh at foolish ones, while being shown the superiority of what the orator proposes" [199]). Mientras que en su autorretrato, Alcaraz usa la distorsión visual para legitimar su visión/punto de vista y así articular el imperativo retórico del "poder"; en la caricatura de Rodriguez, los procesos retóricos funcionan para negar las experiencias de éste y desacreditar su visión/punto de vista, su identidad y hasta su labor como escritor, la cual se representa como el tecleo torpe de un gacetillero.

Alcaraz continúa estableciendo la legitimidad de su visión/punto de vista en la historieta autobiográfica que sigue su autorretrato. Esta narrativa empieza con un relato

9 Véase Tomás Rivera, "Richard Rodriguez’s Hunger of Memory as Humanistic Antithesis” (1984), J. A. Marzán, "The Art of Being Richard Rodriguez” (2003) y el libro de Paul Guajardo, Chicano Controvery: Oscar Acosta and Richard Rodriguez (2002).

${ }^{10}$ La promoción de una identidad "chicana” surge de un movimiento político contestario y activista. Para una historia del Movimiento Chicano, véase Lorena Oropeza, iRaza Sí! ¡Guerra No!: Chicano Protest and Patriotism during the Viet Nam War Era (2005), Ignacio M. García, Chicanismo: The Forging of a Militant Ethos among Mexican Americans (1997) y Carlos Muñoz, Jr., Youth, Identity, Power: The Chicano Movement (1989).

Revista Iberoamericana, Vol. LXXVII, Núm. 234, Enero-Marzo 2011,
ISSN 2154-4794 (Electrónico) 
breve sobre cómo sus padres se conocieron en un curso de inglés y luego decidieron cruzar la frontera para que el artista naciera en los EE.UU. Narrar las experiencias de la generación anterior es un tropo muy común en la literatura latina, y es muy parecido a lo que Marianne Hirsch, en el contexto de los hijos de sobrevivientes del Holocausto, describe como la "posmemoria": la adopción por parte de la segunda generación de viejos traumas familiares en la formación de una identidad tanto individual como colectiva. ${ }^{11}$ El relato de la experiencia de los padres de Alcaraz también funciona para articular el segundo imperativo retórico del esquema de Morris; relatar esta experiencia establece el "saber" de Migra Mouse al crear y provocar interés en un "problema", generar un sentido de crisis intelectual, identificar la naturaleza de esta crisis, señalar sus síntomas y proponer un curso de acción como el remedio eficaz de la misma ("creating and exciting interest in a problem, generating a sense of intellectual crisis, identifying the nature of this crisis, pinpointing its symptoms, and proposing a course of action as the effective remedy" [199]). El "problema” que esta posmemoria identifica es el trauma de cruzar la frontera entre México y los EE.UU., sobre todo la paradoja de la fluidez geográfica entre las dos naciones y las obstrucciones políticas que las separan.

A través de la experiencia familiar, Alcaraz provoca interés en el problema de la frontera y personaliza la crisis intelectual de la doble identidad del sujeto fronterizo. Además, el artista vincula su historia familiar con sucesos históricos de gran importancia; su madre, después de enterarse de que está embarazada, oye la noticia del asesinato del presidente John F. Kennedy (12). La secuencia de los paneles no sigue un orden estrictamente cronológico y emplea la técnica de la analepsis (retrospección) para mostrar que las circunstancias de cómo y dónde se conocieron sus padres influyeron en su decisión de nombrar a su primer hijo con un nombre sólidamente angloamericano: Edward. Los padres, con sus esfuerzos tentativos en inglés, finalmente pronuncian el nombre, pero también pronostican lamentándose que sus futuros amigos lo llamarán "Lalo". Es decir, el nombre angloamericano no le va a borrar sus orígenes mexicanos. El último panel (Figura 4) de esta posmemoria representa a la nueva familia cruzando la frontera entre Tijuana y San Diego, California. Este panel claramente plantea el "saber" del resto de la obra al señalar que los inmigrantes a los EE. UU. cruzan la frontera para buscar más oportunidades de empleo, pero resienten el orden legal y la jerarquía social y racial del "monstruo" del norte. En el panel, la madre acurruca al bebé mientras dice, "Siempre tendrás mucho trabajo, mijito" ("You will always have lots of work mijito" [14]). El bebé lleva una expresión de asombro y aparece un signo de interrogación sobre su cabeza. El padre, con un ademán de disgusto, le entrega a un

${ }^{11}$ En mi ensayo sobre la obra de la escritora puertorriqueña Judith Ortiz Cofer, examino esta noción de Marianne Hirsch en más detalle. Véase “Recuerdos 'parciales' y el closet de la literatura: Ficción y autobiografía de Judith Ortiz Cofer” (2005). Hirsch desarrolla su noción de la "posmemoria” en su libro, Family Frames: Photography, Narrative, and Postmemory (1990).

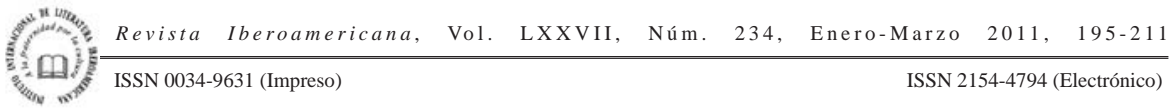




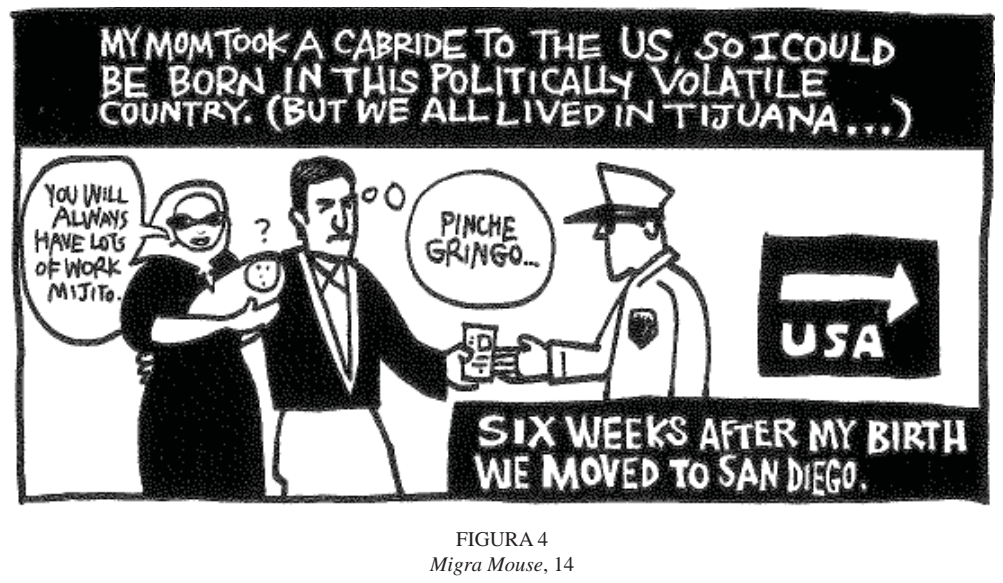

oficial estadounidense sus credenciales mientras piensa, "Pinche gringo". A la derecha extrema del panel se ve un letrero que dice "USA" con una flecha señalando el otro lado de la frontera. El texto que acompaña la imagen revela, a través de otra analepsis, que la madre había cruzado la frontera anteriormente para dar a luz a Alcaraz en los EE.UU., y que seis semanas después cruzó toda la familia definitivamente. Esta revelación señala uno de los "síntomas" de la crisis de la frontera: la práctica de cruzar la frontera para que un hijo nazca en EE.UU. y adquiera automáticamente la ciudadanía estadounidense. El signo de interrogación sobre la cabeza del bebé sugiere la confusión que el sujeto fronterizo siente cuando trata de reconciliar su identidad mexicana con su nacionalidad estadounidense, sobre todo, como en este caso, cuando el individuo no tiene ningún poder de decisión sobre el lado de la frontera en el que va a nacer.

En el relato de posmemoria que inicia la historieta autobiográfica de Migra Mouse, el "saber" es un conocimiento intelectual que afirma la legitimidad del sujeto fronterizo (su nombre sólidamente angloamericano, su ciudadanía estadounidense), desmintiendo, así, cualquier contrincante que opine que no es auténticamente norteamericano. Sin embargo, el "Pinche gringo" del padre afirma el poder subversivo del sujeto fronterizo, permitiendo, de esta forma, que el lector pueda reírse de la opinión nativista desde un espacio discursivo opositor. Esta subjetividad paradójica, que simultáneamente ocupa lugares internos y externos en relación al "monstruo", está constituida por el "problema" de la frontera, pero no necesariamente por la experiencia de haberla cruzado. El signo de interrogación que flota sobre la cabeza inocente del bebé sugiere que el destino de este sujeto fronterizo es inseguro; algo más tendrá que intervenir para que se formule definitivamente. Por consiguiente, la incongruencia que estructura la retórica visual de esta historieta constituye la crisis de identidad de dicho sujeto, y este relato inicial le confiere credibilidad a la solución chicanista que el artista propondrá sucesivamente.

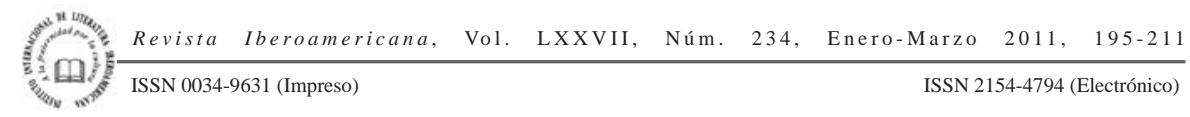


A través de la relación de confianza que el historietista establece con un público cómplice que comparte sus valores y se fía de su visión/punto de vista, la retórica visual de la caricatura política funciona de la misma manera que la estructura narrativa del chiste, como lo ha teorizado Freud. Según el psicoanalista, un chiste provoca risa cuando la persona que cuenta el chiste (la primera persona) logra representar al objeto de la risa (la segunda persona) de forma ridícula o absurda a un oyente cómplice (la tercera persona) (176-77). La segunda persona normalmente está ausente cuando se cuenta el chiste, y así los cómplices tienen la libertad de sentir placer al burlarse de ese objeto. En las caricaturas de Alcaraz, el artista se dirige a un público que comparte su ideología política y su identidad chicana/latina. La segunda persona ausente -el objeto de la risaen la mayoría de las imágenes de Migra Mouse es el estadounidense blanco y nativista, representado consistentemente como un conservador intolerante, racista y elitista. De vez en cuando, Alcaraz caricaturiza a los latinos asimilacionistas, como el escritor Richard Rodriguez que hemos visto, pero es el "pinche gringo" el objeto que recibe las más audaces burlas del artista. La complicidad entre el artista y su público refleja lo que Morris identifica como el tercer imperativo retórico de las caricaturas políticas: el “deber”. Este imperativo se centra en la necesidad de recetar metas morales y normas para el público en relación a la gente y los valores que se han identificado como heroicos o viles ("Devoir centers on the need to prescribe moral goals and rules for the audience in relation to the people and values that have been identified as heroic or unheroic" [199]). Además, este "deber" implica una serie de acciones consideradas necesarias para solucionar el "problema" que la caricatura plantea, pero, como sugiere Greenberg, puede tratarse más bien de persuadir al público para adoptar una actitud en vez de tomar acción directa (185).

Para desarrollar el imperativo retórico del "deber", Alcaraz revela en su historieta autobiográfica (Figura 5) la manera en que él adquirió una conciencia política a través de suparticipación en el Movimiento Estudiantil de Chicanos de Aztlán (MEChA), una de las varias organizaciones que promueven la

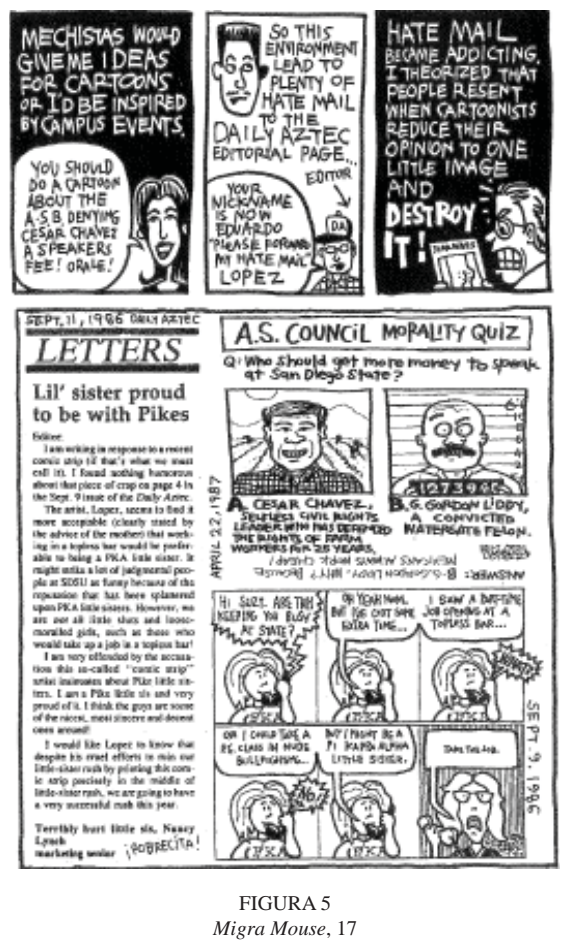

Revista Iberoamericana, Vol. LXXVII, Núm. 234, Enero-Marzo 2011, $195-211$
ISSN 2154-4794 (Electrónico) 
política activista del Movimiento Chicano. ${ }^{12}$ En una secuencia de paneles que relata sus experiencias como estudiante universitario, Alcaraz reconoce la influencia de este grupo en la formación de su propia visión artística. Los Mechistas le entregaban ideas para sus caricaturas, o él mismo se inspiraba de los acontecimientos universitarios, como la discriminación burocrática contra el activista César Chávez y la presencia nociva de extremistas de derecha, como G. Gordon Liddy (Migra Mouse 16-17). Como arguye Morris, el imperativo retórico del "deber" refleja un conocimiento político, y la manera en que Alcaraz contrasta caricaturescamente estas figuras muestra claramente el "deber" que comparte con su público cómplice. En un ejemplo de condensación, que reduce metonímicamente una vasta complejidad a un individuo o símbolo singular (Morris 200, Greenberg 187), el artista usa a las figuras de Chávez y Liddy para representar a todos los chicanos y sus héroes como pulcros, sonrientes y nobles, mientras que los blancos son soeces, beligerantes e inmorales. Hay que reconocer que en toda la colección de Migra Mouse, no hay una sola representación simpática del "pinche gringo", lo cual muestra una intransigencia de la visión fronteriza y su discurso subversivo y opositor.

Apesar de que el imperativo retórico del “deber” en sus caricaturas comparte algunas estructuras discursivas con el chiste freudiano, la publicación de estas imágenes en un medio masivo complica la noción de que el objeto de su burla esté "ausente". Tanto el público cómplice como el objeto caricaturado tienen acceso a la imagen, y su autor está claramente identificado en su firma al pie de la misma. La caricatura provoca risa pero también puede levantar la ira de la gente que valora la figura ridiculizada. En este sentido, el efecto subversivo de las caricaturas de Alcaraz tiene afinidad con el relajo mexicano, sobre todo en la articulación del “deber” que provoca una reacción colectiva. En el relajo, hay un rechazo rotundo por algún valor social que se caricaturiza por su pomposidad y vileza. Jorge Portilla, el filósofo mexicano y autor de La fenomenología del relajo (1966), define el relajo mexicano

[...] como la suspensión de la seriedad frente a un valor propuesto a un grupo de personas. Esta suspensión es realizada por un sujeto que trata de comprometer a otros en ella, mediante actos reiterados con los que expresa su propio rechazo de la conducta requerida por el valor. Con ello, la conducta regulada por el valor correspondiente es sustituída [sic] por una atmósfera de desorden en la que la realización del valor es imposible. (25)

En el caso de las caricaturas de Alcaraz, toda la cultura angloamericana -con sus valores de patriotismo, asimilación étnica/racial, superioridad del inglés y excepcionalismo

12 MEChA es un grupo que promueve la educación y el orgullo cultural y racial de la comunidad chicana. No obstante, el militarismo del grupo es evidente en el símbolo que ha adoptado: un águila feroz que lleva un hacha de batalla en una garra y una dinamita encendida en la otra. Véase su página de Internet: <http:// www.nationalmecha.org/>.

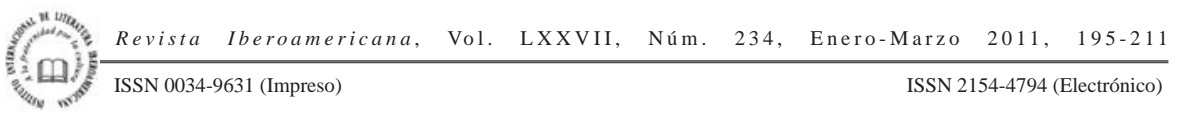


estadounidense- queda rechazada y anulada a través del compromiso al que invita su relajo entre el público chicano. La ira que levanta en un público no-chicano, que toma en serio los valores rechazados, fomenta un ciclo de ataque subversivo y esfuerzo por restablecer el orden mayoritario, lo cual promueve la reiteración del relajo, es decir, la publicación continua de más caricaturas. Como dice Morris, la posición social del caricaturista es influenciada tanto por su "comunidad de referencia" como por su papel como miembro de la prensa (197). El relajo de la caricatura política también implica un imperativo de "deber” porque opera para motivar una acción colectiva, pero el relajo no necesariamente reemplaza los valores que subvierte con valores alternativos. En este sentido, cuando el sujeto que "echa relajo" y su público cómplice rechazan un valor, es el proceso retórico de la carnavalización que capitaliza en esa subversión colectiva para ofrecer otro sistema de valores y reemplazar los que el relajo había negado. Así, el caricaturista y el público concuerdan en una identidad formada en las acciones o actitudes que niegan y oponen. Esas acciones o actitudes colectivas llevan a esta comunidad a buscar valores alternativos, los cuales sí se toman en serio como moralmente correctos y superiores.

Para Alcaraz y el público cómplice que disfruta de sus caricaturas, su "deber" colectivo de rechazar y oponerse a la cultura y sociedad angloamericanas no surge de un vacío; al contrario, el relajo colectivo que comparte esta comunidad refleja una reacción a la discriminación, la injusticia y el abuso violento que han sido la cruda realidad para muchos inmigrantes latinos. En este clima hostil, las caricaturas de Alcaraz y el relajo colectivo que provocan canalizan el disgusto, la indignación y la ira de la comunidad asediada por la discriminación. Según Morris, para que el orador, en este caso el artista gráfico, y su público puedan cumplir con su "deber”, la caricatura política articula un imperativo retórico del "querer" (199). Este "querer” se centra en la promoción del deseo de acción a través de la provocación de una reacción emocional que favorece tanto el diagnóstico [del "problema"] como a su orador, y que es suficientemente fuerte para superar la inercia, resistencia intelectual y el pesimismo sobre la eficacia de cualquier acción propuesta ("Vouloir centers on promotion of the desire for action by exciting an emotional response that is favorable to both the diagnosis and the orator and that is sufficiently strong to overcome inertia, intellectual resistance, and pessimism about the effeciency of any proposed action" [199]). Las caricaturas de Alcaraz canalizan la ira de la comunidad chicana, pero el artista también reconoce que una de las emociones que trata de provocar es el odio de sus enemigos políticos. En la historieta autobiográfica de Migra Mouse, relata cómo el editor del periódico que publicaba sus imágenes recibía cartas de odio de gente ofendida por sus caricaturas (Figura 5). Dice el artista que recibir las cartas de odio se convirtió en una adicción para él, porque le comprobaron el poder que tenía de destruir las opiniones de otros con una sola imagen ("Hate mail became addicting. I theorized that people resent when cartoonists reduce their opinion to one little image and destroy it!") (Migra Mouse 17). Reproduce con cierto orgullo

Revista Iberoamericana, Vol. LXXVII, Núm. 234, Enero-Marzo 2011, $195-211$
ISSN 0034-9631 (Impreso) 
varias cartas de odio que había recibido a lo largo de su carrera, lo cual muestra que sus caricaturas intencionalmente se dirigen a un público que no comparte sus valores. ${ }^{13} \mathrm{El}$ conocimiento emocional que aporta el imperativo retórico del "querer” es una navaja de doble filo porque, por un lado, convoca a una comunidad para tomar acción o adoptar una actitud pero, por otro lado, agrava las divisiones sociales y étnicas/raciales que causan el "problema” de la frontera, en primer lugar.

Al final de la historieta autobiográfica, Alcaraz reafirma su compromiso de crítica a las injusticias de la política de inmigración, pero también asevera que las personas que lo critiquen a él tienen todo el derecho de lanzarse en un cohete para la nueva frontera del espacio sideral: "So everybody can take their official language, manifest destiny, elitist, lineage worshipping, self hating nalgas to the next frontier if you don't like it. Migration is your right as a human being. Send me a postcard" (25). Parado al lado de un cohete nombrado Mayflower 2 (Figura 6), el artista se autorretrata una vez más sugiriéndole a esos descendientes de los peregrinos ingleses que se larguen del planeta si no quieren reconocer el derecho humano de la migración. En esta imagen, la condensación reduce todo tipo de migración a la inmigración, y los peregrinos fundadores son tan culpables como los mexicanos indocumentados que cruzan la frontera actualmente. Através de la carnavalización, invierte las invectivas que normalmente se asocian con grupos nativistas que tratan de legitimar su presencia en los EE.UU. mientras se la niegan a otros.

Enlaelaboración de suhistorieta autobiográfica, Alcaraz revela que su subjetividad fronteriza es constituida por los imperativos retóricos de su arte gráfico. Además, la narrativa es enmarcada por un discurso de descendencia, el cual está en el centro de la política nativista que sus caricaturas ridiculizan. Es decir, empieza su historieta autobiográfica con el enfoque en sus padres, legitimando su nacimiento en los EE.UU.y, así, declarando su derecho de articular su voz y visión. Termina esta narrativa expulsando

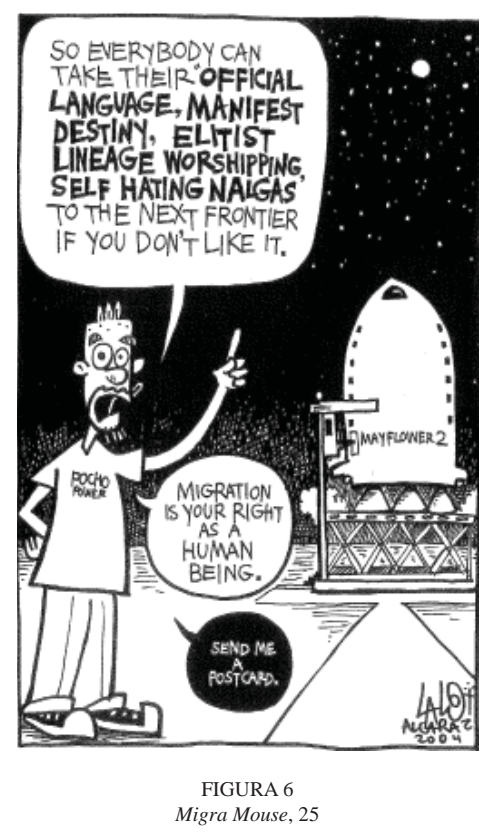

13 En una entrevista con la autora y crítica española Ana Merino, Alcaraz habla de un caso particular de
una carta de odio que le llegó de otro latino que estaba avergonzado de las caricaturas del artista. Alcaraz
comenta que la carta le pareció patética porque su autor había invertido tanta emoción en ella, pero es
innegable que las caricaturas políticas dependen de las reacciones emocionales del público. (Merino
123).
ISTSN 2154-4794 (Electrónico) 
a los descendientes de los peregrinos ingleses que, desde el punto de vista de la política chicana, son los verdaderos inmigrantes ilegales. ¿Cuáles son las implicaciones éticas de este discurso de descendencia? En un estudio de las autobiografías de jóvenes negros en Noruega, Marianne Gullestad arguye que los autores de estos textos adoptan el discurso de descendencia que tiene el potencial no sólo de acomodar múltiples, contradictorios y cambiantes roles e identidades, sino también de neutralizar la discriminación racial, afirmando, de esta forma, su dignidad y amor propio ("Discourses of descent have a potential not only for accommodating multiple, contradictory, and changing roles and identities but also for neutralizing racial discrimination, and thus for dignity and selfrespect" [239]). Sin embargo, la adopción de este discurso de descendencia, como en el caso de la historieta de Alcaraz, paradójicamente refuerza socialmente la categoría racial que la cultura mayoritaria ha utilizado para mantener al inmigrante al margen. Dice Gullestad de los escritores negros en Noruega que "Mientras resisten las ideas dominantes impuestas sobre ellos, se inscriben a sí mismos en esas mismas ideas. Por consiguiente, paradójicamente, esta solución simultáneamente implica una auto-imagen más sostenible para el individuo, una base para la acción colectiva a través de diferencias de origen y experiencias, y un refuerzo social de la categoría racializada" "While resisting dominant ideas about themselves, they inscribe themselves into those very same ideas. Thus, paradoxically, this solution simultaneously implies a more sustainable self-image for the individual, a basis for collective action across differences of background and experiences, and a social reinforcement of the racialized category" [239]).

La diferencia entre los negros noruegos y los chicanos estadounidenses es que éstos reclaman su identidad como los habitantes originales de las Américas, sobre todo en la noción de Aztlán, mientras que aquéllos remontan sus orígenes a otro continente lejano. Por consiguiente, el dedo de Migra Mouse, que habíamos visto señalándoles a los inmigrantes mexicanos la dirección para que vuelvan a su país de origen, al final de la historieta se convierte en el dedo del artista, que les señala a los descendientes de los peregrinos ingleses la dirección para que se larguen del planeta. Esta inversión carnavalesca de la política nativista muestra claramente el poder subversivo de la caricatura y el relajo que provoca. Dice Greenberg que los caricaturistas políticos construyen sus versiones de las "noticias" contra un trasfondo de suposiciones sobre el mundo social, suposiciones que esperan compartir con una comunidad implícita de lectores (“[...] political cartoonists will construct their accounts of the 'news' against a backdrop of assumptions about the social world, assumptions they expect to share with an implied readership community" [195]). Como historietista y caricaturista de prensa por profesión, Alcaraz depende de la agudización de las controversias y los debates sobre la frontera; sin controversia, el creador carece tanto de material como de retórica con que representarla. Por extensión, el sujeto que emerge de su historieta autobiográfica es constituido por la escisión irreconciliable entre culturas, idiomas y naciones. Irónicamente, el sujeto

Revista Iberoamericana, Vol. LXXVII, Núm. 234, Enero-Marzo 2011, $195-211$
ISSN 2154-4794 (Electrónico) 
fronterizo que emerge de la retórica visual de Migra Mouse sufre de una transferencia inadvertida, desplazando su propio nativismo y resentimiento hacia el “pinche gringo" de turno, es decir, el "monstruo" que tiene la desdicha de aparecer en las noticias cualquier día de la semana. En gran parte, los imperativos retóricos de esta historieta reproducen el discurso de rechazo y la negación contra el cual los activistas chicanos han luchado constantemente. Por eso, la historieta autobiográfica que Alcaraz ofrece para explicar cómo sus experiencias le han llevado a desarrollar su visión y punto de vista sobre la frontera, puede dejar bizco al lector cuando se considera que la estructura está dada por la retórica visual de sus imágenes y son estas mismas las que le dan sentido a la narrativa de sus experiencias personales.

BiBLIOGRAFÍA

Alcaraz, Lalo. La Cucaracha. Kansas City: Andrews McMeel Publishing, 2004. Migra Mouse: Political Cartoons on Immigration. New York: RDV Books, 2004.

Bakhtin, Mikhail. Rabelais and His World. Hélène Iswolsky, trad. Cambridge: MIT P, 1968.

Dorfman, Ariel y Armand Mattelart. Para leer al Pato Donald [1972]. México: Siglo XXI, 1978.

Eakin, John Paul. How Our Lives Become Stories: Making Selves. Ithaca: Cornell UP, 1999.

Freud, Sigmund. Jokes and Their Relation to the Unconscious [1905]. James Strachey, trad. New York: Norton, 1960.

García, Ignacio M. Chicanismo: The Forging of a Militant Ethos among Mexican Americans. Tucson: U of Arizona P, 1997.

Greenberg, Josh. "Framing and Temporality in Political Cartoons: A Critical Análisis of Visual News Discourse”. The Canadian Review of Sociology and Anthropology 39/2 (2002): 181-98.

Greimas, A.J. y J. Courtès. Semiotics and Language: An Analytical Dictionary. Larry Crist, trad. Bloomington: Indiana UP, 1982.

Guajardo, Paul. Chicano Controversy: Oscar Acosta and Richard Rodriguez. New York: Peter Lang, 2002.

Gullestad, Marianne. “Tales of Consent and Descent: Life Writing as a Fight against an Imponed Self-Image”. The Ethics of Life Writing. Paul John Eakin, ed. Ithaca; London: Cornell UP, 2004. 216-43.

Hirsch, Marianne. Family Frames: Photography, Narrative, and Postmemory. Cambridge: Harvard UP, 1977.

Jacobson, Robin Dale. The New Nativism: Proposition 187 and the Debate over Immigration. Minneapolis: U of Minnesota P, 2008.

Revista Iberoamericana, Vol. LXXVII, Núm. 234, Enero-Marzo 2011, $195-211$
ISSN 0034-9631 (Impreso) 
Marzán, J.A. “TheArt of Being Richard Rodriguez”. Bilingual Review 27/1(2003): 45-64. Merino, Ana. “The Lalo Alcaraz Interview”. The Comics Journal 270 (2003): 107-23. Morris, Ray. "Visual Rhetoric in Political Cartoons: A StructuralistApproach”. Metaphor and Symbolic Activity 8/3 (1993): 195-210.

Muñoz, Carlos Jr. Youth, Identity, Power: The Chicano Movement. New York; London: Verso, 1989.

Oropeza, Lorena. ¡Raza Sí! ¡Guerra No!: Chicano Protest and Patriotism during the Viet Nam War Era. Berkeley: U of California P, 2005.

Parsons, Talcott. The Social System. Glencoe, IL: Free Press, 1951.

The Structure of Social Action: A Study in Social Theory with a Special Reference to a Group of Recent European Writers. New York; London: McGraw-Hill, 1937.

Portilla, Jorge. La fenomenología del relajo y otros ensayos [1966]. México: Fondo de Cultura Económica, 1997.

Press, Charles. The Political Cartoon. Madison, NJ: Farleigh Dickinson UP, 1981.

Reyes, Israel. "Recuerdos 'parciales' y el closet de la literatura: Ficción y autobiografía de Judith Ortiz Cofer”. Revista Iberoamericana LXXI/212 (2005): 847-63.

Ripoll, Carlos. José Martí, the United States, and the Marxist Interpretation of Cuban History. New Brunswick: Transaction Books, 1984.

Rivera, Tomás. "Richard Rodriguez's Hunger of Memory as Humanistic Antithesis”. Tomás Rivera: The Complete Works [1982]. Julián Olivares, ed. Houston: Arte Público Press, 1992.

Rodriguez, Richard. Brown: The Last Discovery of America. New York: Viking, 2002. Days of Obligation: An Argument with My Mexican Father. New York: Viking, 1992.

Hunger of Memory: The Education of Richard Rodriguez [1982]. New York: Bantam Books, 1983.

Online NewsHour: Richard Rodriguez Essays. <http://www.pbs.org/newshour/ essays/richard_rodriguez.html>.

Scott, Joan W. The Politics of the Veil. Princeton: Princeton UP, 2007.

Parité!: Sexual Equality and the Crisis of French Universalism. Chicago: U of Chicago P, 2005.

Only Paradoxes to Offer: French Feminists and the Rights of Man. Cambridge:

Harvard UP, 1996.

“The Evidence of Experience”. Critical Inquiry 17/4 (1991): 773-97. Gender and the Politics of History. New York: Colmbia UP, 1988.

Stavans, Ilán. Latino U.S.A.: A Cartoon History. Lalo Alcaraz, ilus. New York: Basic Books, 2000.

Torres-Saillant, Silvio. “The Latino Autobiography”. Latino and Latina Writers. Vol. 1. Alan West-Durán, ed. New York: Charles Scribner’s Sons, 2004. 61-79.

Revista Iberoamericana, Vol. LXXVII, Núm. 234, Enero-Marzo 2011, $195-211$
ISSN 2154-4794 (Electrónico) 
